\title{
Perception and Practices of Mothers about Feeding Practices of Newborn Babies in Faisalabad, Pakistan \\ Muhammad Asim
}

UCPW- World Health Organization, Faisalabad, Pakistan

Email:masim202@gmail.com

Nazia Malik

Department of Sociology, Government College University, Faisalabad, Pakistan

Aqeela Tabassum

District Demographer, Population Welfare Department, Chakwal, Pakistan

Murtaza Haider

Polio Eradication Officer (PEO), World Health Organization, Faisalabad, Pakistan

Haq Nawaz Anwar

Chairman, Department of Sociology, Government College University, Faisalabad, Pakistan

\author{
Doi:10.5901/mjss.2014.v5n4p662
}

\begin{abstract}
Annually four million neonatal deaths occur around the globe, approximately three-quarters die within the first week of life. Two-thirds of the world's neonatal deaths occur in just 10 countries, mostly in Asia. Pakistan is at number three among these countries. A reported neonatal mortality rate of 49 per 1000 live births, Pakistan accounts for $7 \%$ of global neonatal deaths. A cross-sectional study was carried out on 200 mothers having at least one child less than 15 month of age was selected by multistage sampling technique. The objectives of study were to explore traditional neonatal rearing beliefs and tradition feeding practices to neonate in industrial district Faisalabad, Pakistan. Data was collected on pre-designed questionnaire and analyzed by descriptive statistics. It was found that $83.5 \%$ mothers breastfed and only $37 \%$ exclusive breastfed their youngest child. A majority of the respondents $89 \%$ agreed that baby should be breastfed after immediate of birth. It is also found that $72.5 \%$ respondents agreed that pre- lectal (ghutti) is necessary practice for child after firth and $51 \%$ respondents were in the opinion that ghutti (Pre-lacteal) is necessary to transfer the characteristics of the feeders in child. It is concluded that mothers and families should be motivated to avoid the cultural practices during newborn nourishment. There should be need the active involvement of print and electronic media and seminars to convincing the care takers for optimum breast feeding practices at gross root level.
\end{abstract}

Keywords: breastfeeding, colostrums, ghutti, pre-lectal and neonatal mortality

\section{Introduction}

Initiating breastfeeding within the first hour of birth can prevent $22 \%$ of neonatal deaths, whilst, $16 \%$ of neonatal deaths can be averted if infants under one year are breastfed from day one. Breastfeeding is directly linked to reducing the number of children who die before their fifth birthday. In Pakistan, 78 infants out of 1,000 are dying every year while under-five mortality is 94 deaths per 1,000 live births (Abid, 2011). Traditional and cultural beliefs and values strongly influence breastfeeding practice. Family ritual in child rearing and caring practice influences breastfeeding practices. Culture and religious beliefs are important sources for feeding rituals (Laroia and Sharma, 2006). Avoiding colostrums and giving some pre-lacteal feed and bottle feeding are contributory factors for these preventable diseases which ultimately lead to high infant mortality (Iqbal et al., 2010). These infants can be saved through the natural protection of 
mother's milk without any other supplements for up to the first six months of their lives

Breastfeeding is important determinants of the nutritional status of children, especially for less than two years. According to Pakistan demographic and health survey (PDHS, 2013) only $38 \%$ children exclusively breastfeed for the first six months of life. It shows that complementary foods are often introduced too early in Pakistan. The aim of this study was to investigate perceptions of mothers about feeding practices of new born babies with special attention to the mothers' indigenous knowledge and practices towards breastfeeding and perceptions about pre-lacteal feeding of the new born, Most of the mothers hold the belief that baby should be fed only when he/she start crying and awake from sleep. Even lay person hold the strong belief on giving pre-lacteal feed to the newborn baby regardless of baby's health status or any associated health risk. For that purpose, use of honey is quite common in many Pakistani families. The family's belief about the use of honey as a pre-lacteal feed is that, it would enhance the bonding of baby with their caregivers (Memon et al., 2006). A few families hold the belief that the mother's first milk i.e. colostrums must be discarded and should not be offered to the baby as it is unhealthy. This practice deprives the newborn from immunological benefits of breastfeeding. In this modern era, various areas in Pakistan the prelude of a weaning diet are either too late or too early, which strongly holds the hazardous implications on child health and nutrition. Even breastfeeding mothers restrict various foods that are considered as HOT or COLD, which further effect negatively on breast milk production and maternal nutrition. Consequently, children in early growth period are underprivileged of healthy foods that are necessary for better growth and mental development (Memon et al., 2006).

\section{Materials and Methods}

Methodology used to achieve the required objectives of the present study. Methodology can be defined as the scientific methods or procedures used for the collection of data and information and its analysis as well as its interpretation. This research was conducted in order to determine the Perception of mothers about feeding practices of new born babies in Faisalabad. In order to meet the research objectives, sample of 200 mothers who have at least one child under the age of fifteen months were interviewed at EPI centres in government health facilities i.e. DHQ hospital and Allied hospital Faisalabad. Two big government health facilities were selected from the district Faisalabad, Punjab through multistage sampling techniques. A sample of 200 mothers who have at least one child under the age of fifteen months was interviewed. At the first stage sample size was taken by proportionate method from respective hospitals. The proportion sampling was drawn according to the availability of bed in each hospital. At the second stage 200 mothers were selected purposively in each hospital i.e. Allied Hospital and Civil Hospital 124 and 76 respectively. Descriptive analysis such as frequency distribution, percentage distribution and cross tabulation was made by using SPSS (Statistical Package for Social Sciences) to describe the data.

\section{Result and Discussion}

Table 1 shows that current age of the respondents and researcher was categorized age group at the time of marriage at three different categories i.e. low median and high. At the time of survey $37.5 \%$ mothers belonged to the lower age group $20-27$ years, $30.92 \%$ to the median $28-35$ years and $11.5 \%$ mothers belonged to the age group of $36-43$ years high age group. Majority of the mothers were young which mean age was 29.37 along with standard deviation of 4.88 . All the mothers who were interviewed were in child bearing age. Table shows that age of the respondents' husbands at the time of interview. $37.5 \%$ belonged to the age of $22-30$ years, $39.5 \%$ belonged to the age group of $31-39$ years and $23 \%$ respondents' husbands belonged to the age group of 40 years and above age group. Data shows that mean age of the respondents' husbands were $34.07 \pm 6.58$ years. Table 1 also shows that age of the mothers at the time of marriage. Data shows that $18.19 \%$ respondents were belonged to lower age category 14-20 years, and majority of the respondents $54 \%$ belong to the median age category $21-27$ years and small proportion of the respondents $10.5 \%$ belonged to the higher age category 28-34 years. Similar results found by Hakim et al., (1998) stated that $17 \%$ of teenagers are currently married in Pakistan. Furthermore, data shows that 20\% respondents' husband belonged to the age group of 14-20 years and $27.61 \%$ belonged to the $23-32$ years and $35.62 \%$ respondents belonged to the age group of 33 and above years at the time of marriage. The mean age of the respondents was $27.01 \pm 4.98$ years. 
Table1: Distribution of the respondents according to their current age and age the time of marriage

\begin{tabular}{|c|c|c|c|c|c|c|c|c|c|}
\hline \multicolumn{10}{|c|}{ Current age } \\
\hline Age of Mothers & Freq. & \%age & Mean & S. D & Age of father & Freq. & \%age & mean & \\
\hline $20-27$ & 75 & 37.5 & 24.55 & 2.12 & $22-30$ & 75 & 37.5 & 27.8 & 3.77 \\
\hline $28-35$ & 102 & 51 & 30.92 & 1.90 & $31-39$ & 79 & 39.5 & 34.59 & 4.20 \\
\hline $36-43$ & 23 & 11.5 & 38.21 & 3.42 & $40+$ & 46 & 23 & 43.39 & 4.11 \\
\hline Total & 200 & 100.0 & 29.37 & 4.88 & Total & 200 & 100.0 & 34.07 & 6.58 \\
\hline \multicolumn{10}{|c|}{ Age at the time of marriage } \\
\hline $14-20$ & 71 & 35.5 & 18.19 & 2.78 & $14-22$ & 40 & 20 & 20.22 & 2.71 \\
\hline $21-27$ & 108 & 54.0 & 23.87 & 2.85 & $23-32$ & 136 & 68 & 27.61 & 3.32 \\
\hline $28-34$ & 21 & 10.5 & 30.52 & 3.12 & $33+$ & 24 & 12 & 35.62 & 2.56 \\
\hline Total & 200 & 100.0 & 22.44 & 4.16 & Total & 200 & 100.0 & 27.01 & 4.98 \\
\hline
\end{tabular}

Table 2: Distribution of the respondents according to education and their occupation

\begin{tabular}{|c|c|c|c|c|}
\hline \multirow{2}{*}{ Educational status } & \multicolumn{2}{|c|}{ Mothers } & \multicolumn{2}{|c|}{ Fathers } \\
\hline & Frequency & Percentage & Frequency & Percentage \\
\hline Illiterate & 40 & 27.0 & 29 & 14.5 \\
\hline Up to 5 Grade & 27 & 13.5 & 17 & 8.5 \\
\hline 6 to 10 Grade & 56 & 28.0 & 75 & 37.5 \\
\hline 11 to 14 Grade & 52 & 26.0 & 55 & 27.5 \\
\hline $15+$ & 25 & 12.5 & 24 & 12.0 \\
\hline \multicolumn{2}{|c|}{ Household Monthly income } & \multicolumn{2}{|c|}{ Frequency } & Percentage \\
\hline \multicolumn{2}{|c|}{ Up to 8000} & \multicolumn{2}{|c|}{44} & 22 \\
\hline \multicolumn{2}{|c|}{8001 to 15000} & \multicolumn{2}{|c|}{64} & 32 \\
\hline \multicolumn{2}{|c|}{15001 to 22000} & \multicolumn{2}{|c|}{48} & 24 \\
\hline \multicolumn{2}{|c|}{22001 to 30000} & \multicolumn{2}{|c|}{27} & 13.5 \\
\hline \multicolumn{2}{|c|}{ Above 30000} & \multicolumn{2}{|c|}{17} & 8.5 \\
\hline \multicolumn{5}{|c|}{ Type of family } \\
\hline \multicolumn{2}{|c|}{ Joint } & \multicolumn{2}{|c|}{113} & 56.5 \\
\hline \multicolumn{2}{|c|}{ Nuclear } & \multicolumn{2}{|c|}{87} & 43.5 \\
\hline \multicolumn{2}{|c|}{ Total } & \multicolumn{2}{|c|}{200} & 100 \\
\hline
\end{tabular}

Table shows that $22 \%$ respondents had up to 8000 rupees monthly household income; almost one third of the respondents 32\% had 80001 to 15000 rupees monthly income. 13.5\% respondents had 15001 to 22000 and 8.5\% respondents had more than 30000 rupees household monthly income. Table shows that majority of the respondents $56.5 \%$ were lived in joint family system, whilst $43.5 \%$ respondents were lived in nuclear family system.

Table 3: Frequency distribution the respondents according to breastfeed their children

\begin{tabular}{|l|c|c|c|c|}
\hline \multicolumn{1}{|c|}{ Attitudinal statements } & \multicolumn{2}{c|}{ Yes } & \multicolumn{2}{c|}{ No } \\
\cline { 2 - 5 } & Freq. & \%age & Freq. & \%age \\
\hline Breastfed your youngest child & 167 & 83.5 & 33 & 16.5 \\
\hline Feeding the anything in addition to child with breast milk within six month & 126 & 63.0 & 74 & 37.0 \\
\hline
\end{tabular}

Table 3 shows that $83.5 \%$ respondents stated that they breastfed to last child and $16.5 \%$ respondents did not breastfed to their last child. Similar results found a medical sociologist Batool, (2010) about the pattern of breastfeeding in district Faisalabad. She found that $86.5 \%$ mothers breastfed to their children. In the Islamic and religious context, it is the liability of the mother and family to breastfed continuously up to the age of two years. The above results shows, serious attention should be focused about the impotence of breastfeeding to the children up to the two years. Data shows that $63 \%$ mothers do not exclusive breastfed to her last child and 37\% mothers had exclusive breast fed (EBF) to the last child. In the present study $37 \%$ of mothers had exclusively breast fed their child up to six months. The studies conducted around the globe also supported present study. Kulkarni et al., (2004) in Bangalore Banapurmat et al., (1996) in Davangere and Mushaph et al., (2008) Botswana found that the EFB rates were lower with 40 percent, 26.8 percent and 6 percent 
respectively. Some other Studies from Pakistan Hyderabad Parveen et al., (2009) and Karachi Ali et al., (2011) of Pakistan, Zhejiang Province in China Qiu et al., (2008) and study in Navi Mumbai Madhu, (2009) reported an EBF rate of $64.4 \%, 68.7 \%, 54 \%$ and $70.2 \%$ respectively.

Table 4: Distribution of the respondent according to their perception about breast feeding of new born babies

\begin{tabular}{|c|l|c|c|c|c|c|c|}
\hline \multicolumn{1}{c|}{$\begin{array}{c}\text { Sr. } \\
\text { No }\end{array}$} & \multicolumn{1}{|c|}{ Attitudinal Statements } & \multicolumn{2}{|c|}{ Agree } & \multicolumn{2}{c|}{ Don't Know } & \multicolumn{2}{c|}{ Disagree } \\
\cline { 3 - 8 } & & Freq. & $\%$ & Freq. & $\%$ & Freq. & $\%$ \\
\hline 1 & After birth, baby should be breastfed immediately? & 179 & 89.5 & 5 & 2.5 & 16 & 8.0 \\
\hline 2 & Colostrums has negative effect on child's health? & 46 & 23.0 & 14 & 7.0 & 140 & 70.0 \\
\hline 3 & Breast milk is/was not enough to fulfil water requirement? & 86 & 43.0 & 8 & 4 & 106 & 53.0 \\
\hline 4 & Do you agree that breast feeding should be stopped when mother got ill? & 58 & 29.0 & 11 & 5.5 & 131 & 65.5 \\
\hline 5 & Is packed milk (Feeder) can be create hazardous implications on children health? & 137 & 68.5 & 10 & 5.0 & 53 & 26.5 \\
\hline
\end{tabular}

New born feeding is a major determinant of infants' health and survival. Table 4 shows that majority of the respondents $89.5 \%$ were agreed that after birth baby should be breastfed immediately and $8 \%$ respondent were not agreed that after birth child should be breastfed immediately. Colostrum provides a strenuous source of natural initial food for the newborn and offers immunity and protection against different diseases (Puri, 1976). In Pakistan, orthodox and traditional families have the opinion that the colostrums has negative effect on child's health and it should be discarded, because it may cause lot of diseases. Data shows that $23 \%$ respondents were agreed that colostrums had negative effects on new born baby, whilst 70\% respondents were not agreed that colostrums had negative effects on new born baby. Ali et al., (2011) and Yasmeen, (2006) reported that $14 \%$ and $71 \%$ mothers discarded the colostrums to the new born baby respectively. Affzal et al., (2010) stated that who were started prelacteals, 31.8 percent inclined by their elders, 17.2ercent did not breastfed their babies because of medical reasons, $7.3 \%$ could not fed their baby with colostrums due to ignorance, while 1.9 percent mother were professional and could not feed their babies.

Data shows that some women have the concept that breast milk is not enough to fulfil the water requirement of the child. That's why people have the concept that water should be provide to the infants to fulfil the water requirement. Data shows that $43 \%$ respondents were agreed that breast milk is not enough to fulfil the water requirement of the children whilst $53 \%$ respondents were in the opinion that breast milk is enough to fulfil the water requirement of the child. Breast feeding baby has not any threat of being illness, if mothers got ill. Present study shows that $17 \%$ mothers were in the opinion that breastfeeding should be stopped if mother got ill, and majority of the respondents $65.5 \%$ were agreed that breastfeeding should be continued if mother got ill. The finding of the study of Woldegebriel, (2002) supported the present study, who investigated that two third of the Ethiopian mothers did not breast feed when they were sick and $91 \%$ suggested not to breast feed when child gets sick. A question was asked, can packed milk create hazardous implications on child health? To this $68.5 \%$ respondents were in the opinion that packed milk or feeder milk could create hazardous implication on children's health, $26.5 \%$ respondents were in the opinion that packed milk could not create hazardous implication on child health and $5 \%$ respondents remained indifferent.

Table 5: Distribution of the respondent according to their perceptions about different types of foods and liquids to be consumed by children

\begin{tabular}{|c|l|c|c|c|c|c|c|}
\hline \multirow{2}{*}{$\begin{array}{c}\text { Sr. } \\
\text { No }\end{array}$} & \multicolumn{1}{|c|}{ Attitudinal Statements } & \multicolumn{2}{|c|}{ Agree } & \multicolumn{2}{c|}{$\begin{array}{c}\text { Don't } \\
\text { Know }\end{array}$} & \multicolumn{2}{c|}{ Disagree } \\
\cline { 3 - 7 } & \multicolumn{1}{|c|}{ Freq. } & $\%$ & Freq. \% & Freq. & $\%$ \\
\hline 1 & Ghutti is necessary for child & 145 & 72.5 & 12 & 6 & 43 & 21.5 \\
\hline 2 & Ghutti (Pre-lacteal) is necessary to transfer the characteristics of the feeders in child? & 102 & 51 & 24 & 12 & 74 & 37.0 \\
\hline 3 & Is Choarca essential to eradicate constipation of child? & 151 & 75.5 & 18 & 9 & 31 & 15.5 \\
\hline 4 & Is gripe water essential for the maintenance of nutritional status of the child? & 161 & 85.5 & 14 & 7 & 25 & 12.5 \\
\hline
\end{tabular}

Some respondents were in the view that there should be some pre-lacteal i.e. Ghutti, honey, water etc. after immediate birth of child. Ghutti is a common cultural practice for new born baby in sub-continent. A majority of the respondents $72 \%$ were in the opinion that Ghutti is necessary for new born babies, and $21.5 \%$ respondents were not agreed that Ghutti is necessary for new born babies. Similar researches conducted by Shahid et al., (2009) found that $49.5 \%$ of the mothers started breastfed after 2 to 3 days of delivery. Similar beliefs are found in Muslim societies, in Bangladesh pre-lacteal 
feeding was found to be given to $77 \%$ of the babies, and honey was given to $72 \%$ of them. In Pakistan Yasmeen et al., (2006) reported that due to the pre-lacteal feeding, breast feeding remained secondary choice for women. Another Indian researcher Kumar et al., (2012) and Ali, (2011) from Pakistan found that 34.9\% and 35\% mothers had given prelacteal feed to the new born respectively. According some Hindu religion, colostrums should be discarded because people having the beliefs that because the thickness and viscosity of colostrums is difficult to swallow and digest. Moreover, there are beliefs that the initial milk is "old or stale" and may cause a number of diseases (Ingram, 2003). Therefore, colostrums should be discarded until normal milk comes. Memon et al., (2006) found that conventional Pakistani mothers have the opinion that colostrums should be discarded for 2 to 3 days because of thickness and staleness. The pre-lacteal feeding of Gutti, honey, tea and water is considered common and important pre-lacteal food for new born baby. Masvie, (2006) examined that it was customarily assumed that mother's breast milk would come on the third day so sugar, water and honey was given to the newborn baby before starting breastfeeding. Kakute et al. (2005) stated that some traditional elders believed that breastfeeding is not able to fulfil the nutritional status of children; breast milk would not increase the infant's weight. So it is important for the child growth to give pre-lacteal foods for their nourishment.

Data shows that more than half $51 \%$ respondents were agreed that Ghutti (Pre-lacteal) is necessary to transfer the inheritance characteristics of the feeders to the new born children, $37 \%$ respondents were not agreed that Ghutti is necessary to transfer the inheritance characteristics of feeders in children, while 18.5\% respondents remained indifferent in this regard. Choracca is considered the part and parcel as an indigenous medicine for the new born baby to eradicate his/her constipation. Data shows that large majority $75.5 \%$ respondents stated that Choracca is essential for to eradicate the constipation of the new born babies, $15.5 \%$ respondents were not agreed that Choracca is essential to eradicate the constipation of the children and 9\% respondents remained indifferent. The next indicator was to known weather grip water is essential to boost up the nutritional status of the child. The respondents that were agreed with this point of view comprised of $80.5 \%$, those that did not had the view that grip water is not necessary to boost up the nutritional status of the children were $12.5 \%$ and the indifferent ones were $7 \%$.

Table 6: Distribution of the respondents according to their perception regarding breast feeding practices of the children

\begin{tabular}{|c|c|c|c|c|c|c|c|}
\hline Sr. & \multirow{2}{*}{ Attitudinal Statements } & \multicolumn{2}{|c|}{ Agree } & \multicolumn{2}{|c|}{ Don't Know } & \multicolumn{2}{|c|}{ Disagree } \\
\hline No & & Freq. & $\%$ & Freq. & $\%$ & Freq. & $\%$ \\
\hline 1 & Do you agree that breast milk should be stopped if baby got ill? & 32 & 16.0 & 15 & 7.5 & 153 & 76.5 \\
\hline 2 & Baby should be fed only when they start crying and awake from sleep? & 118 & 59.0 & 3 & 1.5 & 79 & 40.5 \\
\hline 3 & Have eating hot and cold things by the mother effect badly on child health? & 149 & 74.5 & 12 & 6.0 & 39 & 19.5 \\
\hline 4 & Are Injections cause of side effect during and after pregnancy & 61 & 30.5 & 53 & 26.5 & 86 & 43.0 \\
\hline
\end{tabular}

The next indicator was that do you agree that breast milk should be stopped if baby got ill. Data shows that $16 \%$ respondents were agreed that breast milk should be discard if baby got ill, and a majority of the respondents $76.5 \%$ were in the opinion that when baby got ill breastfeeding should remain continue. The finding of the study of Woldegebriel, (2002) supported the present study, who investigated that two third of the Ethiopian mothers did not breast feed when they were sick and $91 \%$ suggested not to breast feed when child gets sick. To a question on baby feeding patterns, that baby should be fed only when they start crying and awake up from sleep, the responses indicated that a simple majority $59 \%$ respondents were in the opinion that baby should be fed only when he/she start crying for feeding or awake up from sleep, and $39.5 \%$ respondents were in the opinion that child should be fed according to the scheduled time table. Some orthodox women have strong believed that injections have side effects during pregnancy. To analyze the present societal trend toward the shots among the child bearing women, it is found that $30.5 \%$ respondents were agreed that injections have side effects during pregnancy, $43 \%$ respondents were not agreed that injections have side effects during pregnancy and more than one fourth $26.5 \%$ respondents were indifferent opinion in this regard. Response on breastfed women's diet was also be taken. When asked does eating hot and cold eatable thing does effect child health, about a large majority of the respondents $74.5 \%$ were agreed that eating hot and cold eatable things affect the health of children, whilst small proportion of the respondents were not agreed that hot and cold eatable thing affect the child's health. 
Table 7: Chi-Square and Gama values showing relationship between socio-economic characteristics of the respondents and exclusive breastfeeding to their youngest child

\begin{tabular}{|l|c|c|c|c|c|}
\hline \multicolumn{1}{|c|}{ Variables } & Chi-square value & D.F. & Sig. & Gamma value & Sig. \\
\hline Age of the respondents & 6.74 & 2 & $.034^{*}$ & .012 & $.930^{\text {N.S }}$ \\
\hline Mothers education & 5.86 & 4 & $.210^{\text {N.S }}$ & -.213 & $.041^{*}$ \\
\hline Father education & 2.56 & 4 & $.633^{\text {N.S }}$ & -.029 & $.794^{\text {N.S }}$ \\
\hline income & 5.52 & 4 & $.238^{\text {N.S }}$ & .094 & $.389^{\text {N.S }}$ \\
\hline Type of family & .442 & 1 & $.506^{\text {N.S }}$ & -.100 & $.504^{\text {N.S }}$ \\
\hline Number of living rooms & 6.17 & 2 & $.046^{*}$ & .042 & $.726^{\text {N.S }}$ \\
\hline
\end{tabular}

Examine the significance of relationship between socio-economic variables and exclusive breastfeeding of the children chi square and gamma tests are applied. The result of the test indicated that age of the respondents and number of living rooms are significant at 5\% level of significance with their chi square value 6.74 and 6.17 respectively reflecting the association of these variables with exclusive breastfeeding. The positive gamma values the direct and positive association between the variables.

The variable mother and father education, income, type of family are not associated with exclusive breastfeeding. The chi square and gamma values indicate that there is no association between variables and exclusive breastfeeding. Mothers and fathers education and type of family are negatively associated with exclusive breastfeeding.

Table 8: Chi-Square and Gama values showing relationship between socio-economic characteristics of the respondents and practices of pre-lacteal (ghutti) feeding to the new born

\begin{tabular}{|l|c|c|c|c|c|}
\hline \multicolumn{1}{|c|}{ Variables } & Chi-square value & D.F. & Sig. & Gamma value & Sig. \\
\hline Age of the respondents & 3.73 & 8 & $.880^{\text {N.S }}$ & .102 & $.303^{\text {N.S }}$ \\
\hline Mothers education & 24.06 & 16 & $.088^{\text {N.S }}$ & .157 & $.043^{\star}$ \\
\hline Father education & 28.20 & 16 & $.030^{\star}$ & .152 & $.075^{\text {N.S }}$ \\
\hline income & 29.66 & 16 & $.020^{\star}$ & .046 & $.566^{\text {N.S }}$ \\
\hline Type of family & 13.79 & 4 & $.008^{\star}$ & -.135 & $.223^{\text {N.S }}$ \\
\hline Number of living rooms & 19.44 & 8 & $.013^{\star}$ & .095 & $.321^{\text {N.S }}$ \\
\hline
\end{tabular}

The chi-square value of age of the respondents 3.73 and mother's education 24.06 are not associated with dependent variable perfecta feeding whilst gamma value positively and significantly associated mother's education and pre-lacteal feeding. Father's education, household monthly income, type of family and number of living rooms are significant at $5 \%$ level of significance with chi square value $28.20,29.66,13.79$ and 19.44 respectively showing the association between dependent and independent variables. Whilst the gamma values are indicate there is no association between these variables and type of family negatively associated with pre-lacteal feeding of the children.

\section{Conclusion}

Although majority of the mothers were $\mathrm{n}$ the opinion that after birth baby should be breastfed immediately and small proportion of the mothers still have the concept that colostrums has negative on child health. Large majority of the mothers are in favour of pre-lacteal feeding (ghutti) irrespective of highly educational status. Majority of the respondent breastfed to their children but the exclusive breastfeeding rate is worrying. The result of bi-variate analysis shows that mothers and fathers education and household income negatively affect the EBF rate. Child feeding practices are based on so called cultural rituals and traditional values irrespective of the socio economic status of mothers. So, there should be need to crate awareness among mothers about benefits of colostrums, breast feeding, EBF and the harmful impacts of pre-lacteal feeding, and other rearing practices based on cultural values. At micro level LHWs and LHVs are encouraged to consult mothers during antenatal and postnatal care about new born rearing caring practices and health and nutritional problems of their babies. At macro level government and NGOs should take necessary steps by using print and electronic media, holding seminars and engaging public representative about the highlighting the better rearing caring, nourishment and nutritional status of the newborns. 


\section{References}

Abid, N. (2011). Inappropriate feeding practices root cause of malnutrition. The News International. August 5, 2011. http://www.healthynewbornnetwork.org/press-release/inappropriate-feeding-practices-root-cause-malnutrition

Affzal, T., Afzal, S., \& Hassan, U. H. (2010). Pattern of Harmful Practices towards the Newborn in a Pakistani community. Pakistan Armed Forces Medical Journal. 3-9

Ali, M., Asim, M. and Mujahid, T. (2011). Cultural Barriers to Exclusive Breastfeeding By Mothers in a Rural Area Of Cameroon, Africa. Journal of Midwifery and Women's Health, 50, 324-328.

Banapurmath, C. R., Nagaraj, M.C., Banapurmath, S., Kesaree, N. (1996). Breastfeeding practices in villages of Central Karnataka. Indian Paediatric. 33(6):477-9.

Batool, Z. (2010). Socio-Cultural Factors Affecting Anaemia and its Effects on Mother, Child Health in the Rural Areas of District Faisalabad, Punjab, Pakistan. PhD Published thesis, Department of Rural Sociology, University of Agriculture, Faisalabad

Hakim, A., Cleland, J., \& Bhatti, H. M. (1998). Pakistan fertility and family planning survey, 1996-97. National Institute of Population Studies, Islamabad

Ingram, J., Johnson, D., \& Hamid, N. (2003). South Asian grandmothers' influence on breastfeeding in Bristol. Midwifery, $19,318-327$.

Iqbal, S. M. J., Afzal, M. F., Azhar, I.H., \& Sultan, M. S. (2010). First Feed in Newborn: are We Following WHO Recommendations? ANNALS. 16 (4)

Kakute, P. N., Ngum, J., Mitchell, P., Kroll, A. K., Forgwei, G. W., Ngwang, L. K., et al. (2005). Cultural barriers to exclusive breastfeeding by mothers in a rural area of Cameroon, Africa. Journal of Midwifery and Women's Health, 50, 324-328.

Kulkarni, R. N., Anjenaya, S., Gujar, R. (2004). Breast Feeding Practices in an Urban Community of Kalamboli, Navi Mumbai. Indian Journal Community Medicine. 29(4):179-80. Masvie, H. (2006). The role of Tamang mothers-in-law in promoting breastfeeding in Makwanpur District, Nepal. Midwifery, 22, 23-31.

Kumar, N., Unnikrishnan, B., Rekha, T., Mithra, P., Kulkarni, V., Papanna, K. M., Holla, R., \& Jain, A. (2012). Infant feeding and rearing practices adapted by mothers in Coastal South India. International Journal of Collaborative Research on Internal Medicine \& Public Health. 4(12): 1988-99

Laroia, N., \& Sharma, D. (2006). The religious and cultural bases for breastfeeding practices among the Hindus. Breastfeed Medicine, 1 , 94-98.

Madhu, K., Chowdary, S., Masthi, R. (2009). Breast feeding practices and newborn care in rural areas:a descriptive cross-sectional study. Indian Journal of Community Medicine. 34(3):243-6.

Memon, Y., Sheikh, S., Memon, A., \& Naheed, M. (2006). Feeding beliefs and practices of mothers and caregivers for their infants. Liaquat University of Medical and Health Sciences, 8-13.

Mushaph, L.F, Mbhenyane,X. G., Khoza, L.B., Amey, A. K. A. (2008). Infant-feeding practices of mothers and the nutritional status of infants in the Vhembe District of Limpopo Province. South African Journal of Clinic and Nutrition. 21(2):36-41.

Parveen, N., Majeed, R., \& Khawaja, M.A. (2009) Evaluation of breast feeding practices. Gomal Journal of Medical Sciences. 7(1):14-6.

PDHS. (2013). Pakistan demographic and health survey. Preliminary report. National institute of population studies, Islamabad, Pakistan.

Puri, R. K., Khanna, K. K., \& Kumar, G. A. (1976). Infant feeding and child rearing methods in Pondicherry, South India. Indian Journal of Pediatraric.1976; 43(11):323-332.

Qiu, L., Zhao, Y., Binns, C. W., Lee, A. H., \& Xie, X.A. (2008) cohort study of infant feeding practices incity, suburban and rural areas in Zhejiang Province, PR China. International Breastfeed Journal. 3:4.

Shahid, F., Khan, M. H., Ahmad, M., Arshid, M., Khan, W. M., \& Arshad, M. (2009). Infants feeding; Beliefs and practices of Mothers. Professional Medical Journal. 16(2): 274-78

Woldegebriel A. (2002). Mothers' knowledge and belief on breast feeding. Ethiop Med J. 40(4):365-74. 